\title{
Dispatch
}

\section{Critical Pedagogy: Stem Cell Research as it Relates to Bodies, Labor and Care}

\author{
KATAYOUN CHAMANY
}

The New School, USA

As biomedical research has come to depend on human bodies, tissues, and cells, students pursuing life science education need to navigate ethical issues associated with biospecimen collection. These biological resources are valued differently depending on characteristics such as race, class, and gender. For instance, people with unique biological or physical characteristics can provide cord blood in exchange for educational scholarships or housing subsidies. In egg-sharing schemes the "donation" of a portion of one's human eggs to human embryonic stem cell research can result in reduced costs of assisted reproductive services (Dickenson \& Idiakez, 2008). As a consequence of these public contributions of biospecimens, a delicate relationship between the public and private sector is evolving, raising questions about ownership, compensation, access, and privacy. Additionally, as genetic factors influence the value of these biospecimens, they also pose concerns about eugenics (Klitzman \& Sauer, 2015). To address this changing landscape, an interdisciplinary team of scholars and activists embarked on a curriculum development project to promote scientific innovation and socially just practices. The product of this effort is Stem Cells Across the Curriculum (SCAC, n.d.), an open access educational resource that highlights the transactional nature of life science research by integrating the biological and social dimensions using a social justice framework. ${ }^{1}$

\footnotetext{
${ }^{1}$ Stem Cells Across the Curriculum (SCAC) may be accessed atwww.stemcellcurriculum.org. To view SCAC Modules select "Curriculum and Cases." To view Artwork, Infographics or Presentations select "Media and Infographics." Specific URLs for web materials are provided in the reference list.
} 


\section{Teaching Biology in Context}

Two decades have passed since critics first challenged the pedagogy associated with science education. In 1990, Sheila Tobias demonstrated that scientific content devoid of interdisciplinary connections is lost on science non-majors who fail to see the relevance in their daily lives (Tobias, 1990). At around the same time, two educators and social activists, Paulo Freire and Myles Horton, discussed the problems associated with decontextualized science learning. In We Make the Road by Walking: Conversations on Education and Social Change they conclude that teaching biology without any social context is a fallacy (Horton \& Freire, 1990).

Today, the intersection of reproductive and regenerative biotechnologies creates an opportunity for bringing social context to the fore (Ikemoto, 2009). Educators can teach basic biological principles and concepts through topics such as in vitro fertilization, embryo screening, and cell transplant therapies. In a traditional undergraduate curriculum these topics would span a series of courses only accessible to the life science major, and rarely address issues of procedural or distributive justice. This approach widens the gap between the scientifically literate and illiterate, and reifies the exclusionary nature of science. Conversely, by hanging these topics onto the central theme of human development, all students are able to see science as central to the challenges that emerge during everyday life including life course events such as reproduction, disease, and aging. Because the material is relevant and familiar, students' confidence builds, allowing them to critically think about how life science research is conducted and in which direction the field should go.

Using a contextualized approach gives students the permission to pose questions regarding scientific investigation, thereby dispelling the misconceptions that science is about remembering facts, obtaining the "right answers," and remaining separated from the general public. Rather, by viewing science as an evolving process that is not only informed by scientists, but other members of society, they receive a more authentic learning experience. By dismantling the exceptional status of science as authority, students are better able to demythologize experts, recognize whose expertise and which voices are missing from the conversation, and become more comfortable with ambiguity. With this approach, students learn that paradigm shifts can prove challenging, and that sometimes the answers to complex problems involve multiple disciplines and methods. Moreover, because biomedical research requires new forms of experimentation and technological development, issues of distributive and procedural justice become more relevant in this context. 


\section{Development of Stem Cells Across the Curriculum}

The development of the Stem Cells Across the Curriculum (SCAC) curriculum was informed by learning theories that underpin case-based teaching and learning, critical pedagogy, and infographic thinking. We intentionally designed flexible modules that could be used on their own, or in combination, in academic programs spanning biology, ethics, gender, race, and disability studies. The modules contain teaching notes and alternative implementation strategies that support customization, allowing instructors to dial the level up or down, depending on their course and student body. Thus, this collection of modules supports the development of socially responsible scientists as well as non-scientists capable of making informed decisions regarding science and health policy. Because of this civic component, New York State Stem Cell Science (NYSTEM) and New School University financially supported the development and dissemination of the project.

By involving faculty steeped in the biological, ethical, political, and social dimensions of stem cell research (SCR) we were able to unpack complex problems and develop curricular resources that do not allow a segregation of the biological from the social. Our team consisted of six faculty members from New School University, one bioethics scholar from Yeshiva University, and one Learning Sciences Scholar from Georgia Tech University. No two faculty members were in the same discipline, though some collaborators had overlapping interests related to SCR and its social dimensions. For instance, three of the faculty members were feminist scholars whose work spanned health psychology, literature, and philosophy. Two faculty members were drawn from the humanities, literature, and religious studies, and four worked in more applied fields such as clinical psychology, health policy, bioethics, and communication design. With respect to social justice teaching, scholarship, and activism, four were active members in community engagement, government appointed committees, and/or grass roots scholarly groups focused on controversial issues regarding biopolitics and emerging biological and reproductive technologies at the local, national, and international level. All were actively teaching in the classroom. The student researchers were treated as junior scholars and had similar dimensional profiles.

\section{Social Justice Framing}

As a first step in developing our project, we used a social justice framework to reorganize topics related to SCR that we found disaggregated across courses offered by the social sciences, humanities, and natural sciences. Topics such as committee composition, recruitment of research participants, funding schemes, informed consent, and clinical trials were organized under the heading of procedural justice, encouraging students to ask: Who gets to 
participate and direct SCR, whether as a policy maker, scientist, tissue donor, or human research subject? Topics such as public and private biobanking, registries and licenses, patents and commercialization, and disability discrimination were organized under the heading of distributive justice. This latter category collectively addresses access to the knowledge and products generated by the SCR field and the potential marginalization of social models of health at the expense of investment in the biomedical approach to address disease and disability (see Figure 1).

\author{
Procedural Justice \\ Ethics Committee Composition \\ Clinical Trials \& Regulation \\ Oocyte Payment \\ Embryo Research \\ stem cells across the curriculum \\ Social Justice Framework \\ Basic Science of SCR \\ Disability Discrimination \\ Commercialization of Patents \\ Public \& Private Biobanks \\ SC Registries \& Licenses \\ Distributive Justice
}

Figure 1. Using a Social Justice Framework to Make Biology Relevant. Topics related to stem cell research are deliberately organized to consider issues of procedural and distributive justice.

Having reorganized the content of the curriculum to encourage active questioning, we turned our attention to pedagogy. Specifically because life science courses are known to be content heavy, lecture-based, and focused on defining terms and explaining processes, we explored student-centered learning approaches that encourage students to take risks, challenge the status quo, and develop higher order thinking skills. Many of our teaching and learning materials reflect Paulo Freire's model of Pedagogy of the Oppressed (Freire, 1970). The learning activities meet students where they are and honor learners' prior life experience, skills, and knowledge.

This social justice framing in content and pedagogy is integrated throughout the project, and can be recognized in: 1) the list of learning resources; 2) information designs that present counter narratives; 3) assignments that incorporate multiple points of view; 4) assessments that cater to multiple intelligences; and 5) the diverse range of stakeholders represented in our materials. Our approach is intended to attract and maintain the interest of students who may not always see how science plays a role in their lives and communities (Harding, 1998). 
As concrete examples of the ways in which SCAC uses a social justice framework, we can look to the curricular modules and consider not only the selection of topics but resources that support social justice frameworks in these contexts. Although many campuses have adopted the book The Immortal Life of Henrietta Lacks by Rebecca Skloot (2010), a critical pedagogy would caution against using this book as a singular anchor (Kumar, 2012). Though it provides a rich narrative for teaching the history of tissue culture and human subjects research, both of which are essential components of SCR, it tells only one narrative, and more importantly, that of an outsider. Our approach in the HeLa Cells \& HPV Genes: Immortality \& Cancer module incorporates resources that offer alternative narratives, providing a more diverse view of the events associated with establishing the first human cancerous cell line. We couple this text to research articles authored by anthropologists and sociologists who tie this story to those who have been historically marginalized by science and to artwork (see SCAC, n.d.: Artworks) that presents counter narratives (Javitt, 2013; Landecker, 1999; Weasel, 2004). For this reason we also recommend the inclusion of Ruha Benjamin's book People's Science as it analyzes government investment in SCR using perspectives from gender, race, and disability studies, to imagine ways that we can simultaneously invest in science and social equity (Benjamin, 2013).

Similarly, the debates surrounding allocation of public health resources towards a social or biomedical approach to health is deeply analyzed in the Disease, Disability \& Immortality: Hope \& Hype module. The voices of those that live with disability are brought forward as a way to broaden students' views on advances made in the name of "cure" (Shakespeare \& Watson, 2002). The goal of cure is further analyzed within the context of a growing number of companies purporting to cure individuals of a variety of neurodegenerative and genetic diseases with no data to support these claims. Students view popular media, research articles, and activist actions that address the challenges associated with therapeutic misconception. $\underline{A \text { Closer }}$ Look at Stem Cells, accessible from the International Society for Stem Cell Research's website, provides students with an example of socially responsible science put forth by a professional society (see ISSCR, n.d.).

In line with our choice of resources, our learning activities also promote alternative interpretations of topics or terms that are often assumed to be value-neutral or commonly understood. In two modules, HeLa Cells \& HPV Genes: Immortality \& Cancer and Disease, Disability \& Immortality: Hope \& Hype, we revisit the definition of "health," and in the Eggs \& Blood: Gifts \& Commodities and Stem Cell \& Policy: Values \& Religion modules we reflect on the definitions of words like "religion," "sacred," "secular," and "dignity." In these activities students begin to learn that though we speak the same language, these terms hold very different cadence for each individual. Similarly, in the Eggs \& Blood: Gifts \& Commodities module we are careful to avoid gendered language, and opt to use phrases such as "individuals who 
provide eggs." Our decision is based on the fact that not everyone who can produce eggs identifies as female, and because some ovarian stem cell research was conducted on individuals seeking sex-reassignment surgery. By dedicating time to explore how language and differently lived experience place value on our practices and beliefs, SCAC questions our assumed shared values and creates space for open dialogue and acknowledgment of different points of view. Because SCAC incorporates issues of social justice using student-centered learning activities, it demonstrates how diverse populations must negotiate differences in ways that move toward inclusiveness.

Because we are moving through a variety of topics and drawing on the humanities, social sciences, and natural sciences, we turned to infographic thinking to integrate all of these perspectives (Pavlus, 2012). We chose to focus on the nature of different stem cell sources in our radial infographic as this is one of the most contentious issues in SCR, raising several social justice issues. We were intentional in having our design address the movement of cells across space and time as they transit from bodies, to labs, to clinics and markets. Our Sources of Stem Cells Radial Infographic (see SCAC, n.d.) contains 55 hyperlinks to multimedia spanning blogs, artwork, film, news, and research articles in an effort to promote integrated learning. Thus, this infographic empowers learners to explore the linked resources based on their interests and familiarity and encourages movement into novel areas by catering to what cognitive science research has revealed as multiple intelligences (kinesthetic, textual, visual, auditory, tactile) (Northern Illinois University).

\section{Critical Case Pedagogy}

To provide a more contextualized view of SCR and to help students develop mental schemas necessary for understanding and later retrieval of content, we felt it was important to provide a thematic focus to the curriculum in the form of case study modules. Case-based Learning (CBL) in the sciences has become a popular approach to interdisciplinarity because the story of the case requires students to view science through a wider, more humanistic lens. A case is "an account of real events that seems to include enough intriguing decision points and provocative undercurrents to make a discussion group want to think and argue about them" (Barnes, Christensen, \& Hansen, 2000). Using case studies in the classroom has a long tradition in higher education, especially in the areas of medicine, business, and law, and was originally pioneered in the Kennedy School for Government and Public Policy.

The premise of CBL is that the cognitive conflict offered by complex realworld problems stimulates learning and initiates inquiry and collaboration by students. Moreover, case studies that incorporate a role-play format support constructivist learning in which students are responsible for building their knowledge base collectively and collaboratively. To that end, the selection of 
real-world characters in the SCAC case studies are intentional and deliberate, representing diverse members of society with respect to values, socioeconomic class, ethnicity, and ability.

The use of CBL has been bolstered by research in cognitive neuroscience, which reveals how story telling and narratives improve learning retention as they help individuals make sense of the world. By crafting a story that includes diverse points of view and a range of different lived experiences, students are presented with opportunities to embody the lives of those that they may never encounter in their every day life, offering them a chance to develop a broader worldview.

In general, CBL has advantages for underrepresented minority students and those who may not learn best through lecture and textbook readings. Indeed, CBL has been considered a promising teaching approach to help overcome the barriers that are rooted in cultural and preparatory differences, especially if combined with Intergroup Dialogue (IGD). Additionally, creating "brave spaces" where conflicting viewpoints are discussed with civility, and individuals are not permitted to opt out of discussion by "agreeing to disagree," promotes learning for personal and social responsibility towards social justice (Arao \& Clemens, 2013).

Each SCAC Case Module reviews basics biological principles and ethical, legal, and social dimensions as can be seen at the table found on the SCAC website (SCAC, n.d.: About the Modules). Each case module can be used on its own, or in combination, and all cases emphasize the value of counter narratives that challenge the "dominant" narrative. By seeing the case study from different vantage points, students recognize that depending on one's context, the "dominant" narrative varies. They identify areas of conflict among stakeholders who hold different values and use ethical reasoning to propose policies that promote scientific innovation and socially responsible practices.

Collectively, the Case Modules move from the history of tissue culture research, to the identification and isolation of embryonic stem cells, to the identification and manipulation of adult cells to enhance cell plasticity, to policies regarding cloning, embryo creation and destruction, biospecimen and egg provider compensation, and biobanking in the public and private sectors.

Within the Case Modules are stories that present an opportunity for roleplay. Here, students are asked to adopt a role and engage in a simulated dialogue based on one that took place among researchers, activists, and policy makers at a real-world conference session or symposium. We were deliberate in emphasizing dialogue, as we found that students often stop listening to each other during debates (Nagda, Gurin, Rodriguez, \& Maxwell, 2008). When students are more concerned about winning the debate they are unwilling to negotiate compromise, or amend their position, shifts that can only come from gaining a broader understanding of an opposing position. Our emphasis on dialogue allows students to grapple with the full complexity of a case analysis and an opportunity to experience shades of grey. We offer 
students a more authentic learning experience by crafting a case narrative that involves real people and events negotiating complex issues for which there are no easy answers.

An example of applying a critical pedagogy to CBL can be seen in the Eggs \& Blood: Gifts \& Commodities module where various views on egg provision for embryonic SCR are presented in an effort to craft a policy proposal regarding compensation. Some stakeholders argue that autonomy to participate in egg provision is critical if gender equity is to be realized, while others raise concerns about the nature of "choice" given the lack of information on long- term health risks, existing economic inequities, and the lack of genetic diversity in existing stem cell lines (Roberts \& Throsby, 2008; Roxland, 2012). This module is a good example of how we refrain from considering the non-biological aspects of SCR as simply downstream issues. It is not only the implications of SCR that engage the ethical, legal and political, but rather the very nature of conducting the research in the first place. If the cell lines are not diverse, then fewer people will be able to use products from this research. Yet, by expanding who can provide eggs for ESCR we may intentionally exploit vulnerable populations. In this module, we have juxtaposed the biological and technical processes involved in egg provision and egg procurement with discussions regarding: 1) compensation; 2 ) equity and access to medical research and treatments; 3 ) health risks for young oocyte providers; 4) informed consent; and 5) the role of regulatory bodies such as the Human Fertilisation and Embryo Authority, Institutional Review Boards, and new ethical oversight committees such as Embryonic Stem Cell Oversight Committees and the most recently proposed Embryo Research Oversight Committee (Emanuel \& Menikoff, 2011; ISSCR, 2016).

\section{Future Directions}

Components of SCAC have been used in multiple institutions and programs including general education, bioethics, and biology courses at San Francisco State University, a minority serving institution; bioethics and reproductive biology course at Vassar College; an anthropology course at Fordham University; and multiple courses at The New School including a summer program serving students from under resourced backgrounds and a university lecture course (see Presentations on the SCAC website). SCAC was also selected as a Model SENCER Course (Science Education for New Civic Engagements and Responsibilities) (NCSCE, 2016). These models are chosen based on their ability to engage students with complex issues that require a rigorous understanding of basic scientific principles and methodologies, connect to issues of civic importance, and provide instructors with appropriate teaching and learning resources that address clear learning outcomes (see SENCER, 2015) 
We are presently analyzing student learning outcomes data from the course implementations of SCAC. Initial directed content analysis of student policy proposals and exams have revealed that we were able to achieve many of our goals. One such goal was broadening students' views of the ethical issues associated with SCR. At the start of each course we ask students to reflect on this and, not surprisingly, they are able to describe the debates surrounding the moral status of the embryos that may be terminated for embryonic SCR. At the completion of a course in which SCAC was implemented students are able to read case studies and move beyond this singular ethical issue, providing detailed and nuanced descriptions. Their responses speak to issues of economic and health equity, care versus cure dichotomies, vulnerable populations, just participant selection in clinical trials, compensation for biospecimens, and access to downstream medical therapies. Case study assignments reveal that students are developing ethical reasoning skills as described by educational psychologist William Perry. The progression of assignments track their development from dualistic thinking to more relativistic thinking, with many able to provide an evidence-based argument to put forth a committed position on a specific SCR-related policy (see The Perry Network, n.d.).

We have begun to map students' comments regarding their own learning in response to the curriculum design and intended learning outcomes. These include: 1) an appreciation for an interactive infographic that allows for the navigation of large amounts of information with ease; 2) a recognition that people need to draw on biology to inform their decisions regarding SCR; and 3 ) a tolerance for multiple points of view. We will continue this mapping project and plan to publish our results in future publications focused on life science and interdisciplinary education. The curriculum is freely available and we intend to refine our materials based on these data and user feedback.

As research on stem cells, climate change, data science, and nanotechnology expands, we will need to address the ethical, legal, and social dimensions in ways that bring the complexity of these fields to the fore. Educational resources that can integrate the scientific and social dimensions provide students with opportunities to develop the skills necessary for interdisciplinary exploration and problem solving. The cases studies found on the Data \& Society Research Institute (n.d.) and the U.S. based National Center for Case Study Teaching in Science (NCCSTS, n.d.) sites are a step in that direction. Case studies that bring the voices of the marginalized to the center highlight the need for a responsive justice approach dependent on interdisciplinary learning. Stem Cells Across the Curriculum and the Enduring Legacies case collection developed by Evergreen College extend standard case-based teaching and learning to issues of social justice (see Enduring Legacies, n.d.), but more efforts like these are needed if we are to meet the challenges of twenty-first century education. 


\section{Acknowledgements}

The author would like to acknowledge Lianna Schwartz-Orbach, Alexa Riggs, and Nancy Pokrywka for their review of this manuscript.

\section{References}

Arao, B., \& Clemens, K. (2013). From safe spaces to brave spaces: A new way to frame dialogue around diversity and social justice. In L. Landreman (Ed.), The art of effective facilitation: Reflections for social justice educators (pp. 135-150). Sterling, VA: Stylus Publishing.

Barnes, L., Christensen, C., \& Hansen, A. (2000). Teaching and the case method: Text, cases, and readings. Cambridge, MA: Harvard Business Press.

Benjamin, R. (2013). People's science: Bodies and rights on the stem cell frontier. Stanford, CA: Stanford University Press.

Data \& Society Research Institute. (n.d.). Retrieved from https://datasociety.net/

Dickenson, D., \& Idiakez, I. A. (2008). Ova donation for stem cell research and international perspective. International Journal of Feminist Approaches to Bioethics, 1(2), 125-144.

Emanuel, E. J., \& Menikoff, J. (2011). Reforming the regulations governing research with human subjects. New England Journal of Medicine, 365(12), 1145-1150.

Enduring Legacies. (n.d.) Enduring legacies: Native case studies. Retrieved from http://nativecases.evergreen.edu/collection/

Freire, P. (1970). The pedagogy of the oppressed. New York: Bloomsbury Academic.

Harding, S. (1998). Is science multicultural? Postcolonialism, feminism \& epistemologies. Bloomington, IN: Indiana University Press.

Horton, M., \& Freire, P. (1990). Ideas: "Is it possible to just teach biology?." In B. Bell, J. Gaventa, \& J. M. Peters (Eds.), We make the road by walking: Conversations on education and social change (pp. 102-109). Philadelphia: Temple University Press.

Ikemoto, L. (2009). Eggs as capital: Human egg procurement in the fertility industry and the stem cell research enterprise. Signs: Journal of Women in Culture and Society, 34, 763782.

ISSCR (International society for Stem Cell Research). (2016, May 12). Guidelines for stem cell research and clinical translation. Retrieved from www.isscr.org/home/about-us/newspress-releases/2016/2016/05/12/isscr-releases-updated-guidelines-for-stem-cell-researchand-clinical-translation

ISSCR (International society for Stem Cell Research). (n.d.) A closer look at stem cells. Retrieved from http://www.closerlookatstemcells.org

Javitt, G. H. (2013). Take another little piece of my heart: Regulating the research use of human biospecimens. Journal of Law, Medicine \& Ethics, 41(2), 424-439.

Klitzman, R., \& Sauer, M. (2015). Kamakahi vs. ASRM and the future of compensation for human eggs. American Journal of Obstetrics \& Gynecology, 213(2), 186-187.

Kumar, R. (2012, August). An open letter to those colleges and universities that have assigned Rebecca Skloot's The Immortal Life of Henrietta Lacks as the "common" freshmen reading for the class of 2016. Brown Town Magazine. Retrieved from http://itsbrowntown.blogspot.ca/2012/08/an-open-letter-to-thosē-colleges-and.html

Landecker, H. (1999). Between beneficence and chattel: The human biological in law and science. Science in Context, 12(1), 203-225.

Nagda, R., Gurin, P., Rodriguez, J., \& Maxwell, K. (2008). Comparing debate, discussion and dialogue handout. Retrieved from www.lwsd.org/SiteCollectionDocuments/About-Us/StudySessions/2015.06.22/Comparing-Debate-Discussion-and-Dialogue.pdf

NCSCE (National Center for Science \& Civic Engagement). (2016, June 28). SENCER model course stem cells and social justice goes modular. Retrieved from http://ncsce.net/sencermodel-course-stem-cells-and-social-justice-goes-modular/ 
NCCSTS (National Center for Case Study Teaching in Science). (n.d.). National Center for Case Study Teaching in Science. Retrieved from http://sciencecases.lib.buffalo.edu/cs/

Northern Illinois University, Faculty Development \& Instructional Design Centre (n.d.). Howard Gardner's theory of multiple intelligences. Retrieved from www.niu.edu/facdev/_pdf/guide/learning/howard_gardner_theory_multiple_intelligences.p $\mathrm{df}$

Pavlus, J. (2012, February 7). Why "infographic thinking" is the future, not a fad. Infographic of the day. Retrieved from www.fastcodesign.com/1668987/why-infographic-thinking-is-thefuture-not-a-fad

Perry Network. (n.d.). The Perry Network: Supporting research and assessment on the Perry scheme of intellectual and ethical development. Retrieved from http://perrynetwork.org/?page id=6

Roberts, C., \& Throsby, K. (2008). Paid to share: IVF patients, eggs and stem cell research. Social Science \& Medicine, 66(1), 159-169.

Roxland, B. E. (2012). New York State's landmark policies on oversight and compensation for egg donation to stem cell research. Regenerative Medicine, 7(3), 397-408.

Skloot, R. (2010). The immortal life of Henrietta Lacks. New York: Random House.

Shakespeare, T., \& Watson, N. (2002). The social model of disability: An outdated ideology? Research in Social Science and Disability, 2, 9-28.

SCAC. (n.d.). About the modules. Retrieved from the Stem Cells Across the Curriculum website: http://www.stemcellcurriculum.org/about-modules.html

SCAC. (n.d.). Artworks. Retrieved from the Stem Cells Across the Curriculum website: www.stemcellcurriculum.org/artworks

SCAC. (n.d.) Disease, Disability \& Immortality: Hope \& Hype. Retrieved from the Stem Cells Across the Curriculum website: www.stemcellcurriculum.org/disease-disabilityimmortality-hope-hype

SCAC. (n.d.). Eggs \& blood: Gifts \& Commodities. Retrieved from the Stem Cells Across the Curriculum website: www.stemcellcurriculum.org/eggs-and-blood.html

SCAC. (n.d.). HeLa cells \& HPV genes: Immortality \& Cancer. Retrieved from the Stem Cells Across the Curriculum website: www.stemcellcurriculum.org/hela-cells-hpv-genesimmortality-cancer

SCAC. (n.d.). Presentations. Retrieved from the Stem Cells Across the Curriculum website: http://www.stemcellcurriculum.org/presentations.html

SCAC. (n.d.). Sources of Stem Cells Radial Infographic. Retrieved from the Stem Cells Across the Curriculum website: http://www.stemcellcurriculum.org/infographics.html

SCAC. (n.d.). Stem Cells Across the Curriculum. Retrieved from www.stemcellcurriculum.org

SCAC. (n.d.). Stem Cells \& Policy: Values \& Religion. Retrieved from the Stem Cells Across the Curriculum website: http://www.stemcellcurriculum.org/stem-cells-policy-values-andreligion.html

SENCER (Science Education for New Civic Engagements and Responsibilities). (2015). The SENCER model series. Retrieved from http://www.sencer.net/resources/models.cfm

Tobias, S. (1990). They're not dumb, they're different: Stalking the second tier. Tucson, AZ: Research Corporation.

Weasel, L. (2004). Feminist intersections in science: Race, gender and sexuality through the microscope. Hypatia, 19(1), 183-193. 